\title{
Artificial Intelligence and the Future of the Drug Safety Professional
}

\author{
Karolina Danysz ${ }^{1}(1) \cdot$ Salvatore Cicirello ${ }^{1} \cdot$ Edward Mingle $^{2} \cdot$ Bruno Assuncao $^{2} \cdot$ Niki Tetarenko $^{2} \cdot$ Ruta Mockute $^{2}$. \\ Danielle Abatemarco ${ }^{2} \cdot$ Mark Widdowson $^{2} \cdot$ Sameen Desai ${ }^{2}$
}

Published online: 20 October 2018

(c) The Author(s) 2018

\begin{abstract}
The healthcare industry, and specifically the pharmacovigilance industry, recognizes the need to support the increasing amount of data received from individual case safety reports (ICSRs). To cope with this increase, more healthcare and qualified professionals are required to capture and evaluate the data. To address the evolving landscape, it will be necessary to embrace assistive technologies such as artificial intelligence (AI) at scale. AI in the field of pharmacovigilance will possibly result in the transformation of the drug safety (DS) professional's daily work life and their career development. Celgene's Global Drug Safety and Risk Management (GDSRM) function has established a series of work activities to drive innovation across the pharmacovigilance value chain (Celgene Chrysalis Fact Sheet. https://www.celgene.com/newsroom/media-library/ chrysalis-fact-sheet/, 2018). The development of AI in pharmacovigilance raises questions about the possible changes in DS professionals' lives, who may find themselves curious about their future roles in a workplace assisted by AI. We discuss the current state of pharmacovigilance and the DS professional, AI in pharmacovigilance and the potential skillsets a DS professional may require when working with AI. We also describe the results of research conducted at Celgene GDSRM. The objective of the research was to understand the thoughts of pharmacovigilance professionals about their jobs. These results are provided in the form of aggregated responses to interview questions based on a 12-part questionnaire [see the Electronic Supplementary Material (ESM)]. A sample of six DS professionals representing various areas of pharmacovigilance operations were asked a range of questions about their backgrounds, current roles and future expectations. The DS professionals interviewed were, overall, enthusiastic about their job roles potentially changing with AI enhancements. Interviewees suggested that AI would allow for pharmacovigilance resources, time, and skills to shift the work from a volume-based to a value-based focus. The results suggest that pharmacovigilance professionals wish to use their qualifications, skillsets and experience in work that provides more value for their efforts. Machine learning algorithms have the potential to enhance DS professionals' decision-making processes and support more efficient and accurate case processing.
\end{abstract}

Electronic supplementary material The online version of this article (https://doi.org/10.1007/s40264-018-0746-z) contains supplementary material, which is available to authorized users.

Karolina Danysz

kdanysz@celgene.com

Celgene International Sàrl, Route de Perreux 1,

2017 Boudry, Switzerland

2 Celgene Corporation, 86 Morris Ave, Summit, NJ 07901, USA

\section{Key Points}

Increases in the number of individual case safety reports require assistive technologies such as artificial intelligence (AI) to support the drug safety (DS) professional with the increasing volume and complexity of work.

Using AI, the DS professional's work life may potentially change as their decision making is augmented and efficiency enhanced.

DS professionals may need to learn new skills and competencies to understand and work with AI. 


\section{Introduction}

\subsection{Background}

For the better part of the past 20 years, not a great deal has changed in how pharmacovigilance professionals handle the processing of adverse drug reaction reports and extraction of health data from individual case safety reports (ISCRs). The systems and processes differ slightly between companies and regulatory bodies but remain essentially the same and can be compared. The regulatory requirements differ from country to country, with local differences, but any health safety issue or report must be relayed to a health regulator in the country in which a product is being investigated, provided or sold.

Through a series of information points, a report is passed from the patient to the national competent health authority via healthcare professionals and drug safety (DS) professionals, who transmit, process and assess this safety information, to ensure the safety of patients and compliance with regulations. Aggregate reports of these single case reports are generated from the data entered into the databases, and analytics are conducted on these reports to discover any additional signals or warnings that a drug manufacturer or regulator should be aware of to ensure public health and safety. More than 1 million reports of drug side effects were received by the US FDA in 2015, a fivefold increase since 2004 [2].

Two imperatives identified to elevate the pharmacovigilance organization's role are (1) capacity management, in which a pharmacovigilance executive needs to improve on timelines and productivity and address the expectations of regulatory agencies; and (2) information and analytics, in which technology needs to deliver significant value across the organization [3].

\subsection{Assistive Technologies}

Automation of jobs and artificial intelligence (AI) have triggered much discussion across all industries that are either affected by or considering developing this technology to aid in their operations. As with any topic, opinions regarding AI differ. One of the most widely discussed questions is whether AI will replace humans in their roles. A 2013 study conducted at Oxford University posited that as many as $47 \%$ of all jobs in the USA are at risk of automation or computerization [4].

One school of thought believes the use of AI will not result in widespread redundancy and humans losing their jobs but will instead create jobs. Research suggests that companies that invest in smart, automated and self-teaching systems are creating jobs. Researchers at Capgemini surveyed 1000 organizations that have deployed AI-based systems and found that four of five organizations had created jobs [5].

Merriam-Webster defines AI as "(1) A branch of computer science dealing with the simulation of intelligent behavior in computers; (2) the capability of a machine to imitate intelligent human behavior" [6].

Machine learning (ML) is an application of AI that provides systems with the ability to automatically learn and improve from experience without being explicitly programmed. ML focuses on the development of computer programs that can access data and use it to learn for themselves [7].

\subsection{The Drug Safety Professional}

From ICSR receipt to submission to regulatory authorities, a multitude of DS team members contribute to a variety of processes. This requires specific knowledge and competencies [8].

King [9] proposed DS/pharmacovigilance core competencies describing DS science knowledge necessary for competent performance as a DS professional. Additional core competencies include analytical/assessment skills, communication skills, leadership and systems thinking skills. Level 1 core competencies apply to an entrylevel DS professional; level 2 core competencies apply to advanced and senior-level DS associates, supervisors and managers; and level 3 core competencies apply to associate directors, directors and DS organization leaders [9]. Table 1 describes one such competency example.

\section{Research}

In November 2016, Celgene Global Drug Safety and Risk Management (GDSRM) embarked on the challenge of developing ML algorithms for use in its pharmacovigilance operations. To apply this technology to pharmacovigilance it would require substantial effort in terms of not only technology development and implementation but also change management.

\subsection{Aim}

Our objective was to understand the general sentiments, expectations and readiness of DS professionals towards AI in pharmacovigilance at Celgene GDSRM. 
Table 1 Drug safety/pharmacovigilance core competencies [9]

\begin{tabular}{|c|c|c|c|}
\hline & \multicolumn{3}{|c|}{ Drug safety/pharmacovigilance core competencies: } \\
\hline & Level 1 & Level 2 & Level 3 \\
\hline $\begin{array}{l}\text { Knowledge } \\
\text { of drug } \\
\text { safety sci- } \\
\text { ences }\end{array}$ & $\begin{array}{l}\text { Identifies prominent events in the history } \\
\text { of drug safety }\end{array}$ & $\begin{array}{l}\text { Distinguishes prominent events in the his- } \\
\text { tory of drug safety }\end{array}$ & $\begin{array}{l}\text { Describes lessons learned from prominent } \\
\text { events in the history of drug safety and } \\
\text { application to the current field }\end{array}$ \\
\hline $\begin{array}{l}\text { Skill sets: } \\
\text { analytical/ } \\
\text { assessment } \\
\text { skills }\end{array}$ & $\begin{array}{l}\text { Basic knowledge of data entry, quality } \\
\text { control, coding, workflow, and report- } \\
\text { producing procedures within validated } \\
\text { safety databases }\end{array}$ & $\begin{array}{l}\text { Advanced knowledge of coding, work- } \\
\text { flow and report-producing procedures } \\
\text { within validated safety databases. } \\
\text { Oversight of quality-control procedures } \\
\text { by level } 1 \text { and other support employees. } \\
\text { Participation in safety database valida- } \\
\text { tion and user acceptance testing }\end{array}$ & $\begin{array}{l}\text { Advanced knowledge of safety data- } \\
\text { base validation procedures, data base } \\
\text { upgrades, database change orders, } \\
\text { database migrations and interaction } \\
\text { with information technology validation } \\
\text { personnel and database administrators. } \\
\text { Advanced application of safety database } \\
\text { workflow tools to daily case processing } \\
\text { by level } 1 \text { and level } 2 \text { professionals }\end{array}$ \\
\hline
\end{tabular}

\subsection{Methods}

\subsubsection{Interviews}

DS professionals were selected at Celgene GDSRM to participate in interviews during a 2-week period in October 2017. Interviews were approximately 1-hour and participants answered a 12-item questionnaire [see Electronic Supplementary Material (ESM)]. This questionnaire was developed by the listed current opinion article authors. The feasibility of the questionnaire was tested by 3 of the co-authors prior to interviewing the study subjects.

\subsubsection{Sampling}

The subjects sampled for the interviews were Celgene DS professionals who: had undergone a recent transition in their role, and/or were assisting in the development of machine learning (ML) algorithms and/or were based in different international offices.

\subsubsection{Measures/Measurement}

The interviewees were anonymized and described by a generic job description and title. The interview results were summarized, and quotes of interest extracted to be incorporated into the discussion of results. The results of the interview were qualitative, and the intention was to understand the thoughts and opinions of Celgene DS professionals regarding potential changes in their daily work lives due to future adoption of AI.

\subsection{Results}

6 DS professionals were selected to participate in this study: $2 / 6$ interviewees were from US headquarters; $3 / 6$ interviewees were from Europe (1/6 European headquarters, 2/6 local European affiliates); 1/6 interviewee was from the Asia-Pacific local DS office; 4/6 interviewees were directly involved with ML algorithm development. Celgene DS professionals provided their views on the future of pharmacovigilance, their roles and the relation between automation with $\mathrm{AI}$ and their future job roles. The answers to the questions were summarized; the questions and the aggregates of the answers are described in the following subsections.

\subsubsection{Question 1: What is your job title/function?}

The Celgene DS professionals had various levels of seniority and a range of work experience. Job roles included (1) a regional affiliate oversight lead senior manager, (2) a senior DS and risk management specialist at an affiliate, (3) a DS and risk manager at an affiliate, (4) a DS and risk management senior manager at an affiliate, (5) a DS specialist and (6) a senior DS specialist working in the pharmacovigilance innovation team.

\subsubsection{Question 2: What are your qualifications?}

All Celgene DS professionals interviewed for the study had a postgraduate education; specializations were in science and health sciences. The degrees included (1) a master's in pharmaceutical chemistry, (2) a master's in microbiology and environmental sciences, (3) an MSc in bio-pharmaceutical sciences, (4) a BSc Hons in microbiology, master's in epidemiology and $\mathrm{PhD}$ in biochemistry, (5) a BA in neuroscience and a postgraduate nursing qualification, (6) a BSc in health science and a doctor of medicine. 


\subsubsection{Question 3: How many years of overall work experience do you have? How many years of pharmacovigilance work experience do you have?}

Work experience ranged between 4 and 16 years of overall work experience in the pharmaceutical and healthcare industry, with pharmacovigilance experience ranging between 3 and 14 years.

\subsubsection{Question 4: What is your current role?}

Three examples of the interviewees' professional roles are as follows:

The role of a regional affiliate oversight lead senior manager entails creating a bridge or connection between the local DS offices and the central function of global DS. In this role, the DS professional supports the affiliates concerning DS questions, risk management programs, resource needs and any issues that require escalation or support.

A senior DS specialist at an affiliate is responsible for all risk management training materials on a website for local affiliate use; training new hires at the office on DS and reporting of adverse events; receipt and follow-up of local cases by sending letters formatted to local requirements and local legislation, and scanning for updates. A DS and risk senior manager/manager at an affiliate is responsible for similar activities in addition to staff management and liaising with external healthcare professionals and health regulators. A senior manager of DS and risk management presented and trained at external pharmacovigilance conferences, thus creating relationships with local health authorities.

Responsibilities of a DS and senior DS specialist working in the pharmacovigilance innovation team included supporting the development of AI in PV and related activities. Their experience in case management equipped them to act as subject matter experts (SMEs) in the pharmacovigilance field.

\subsubsection{Question 5: How did you find yourself in your current role?}

The Celgene DS professionals had previous work experience in clinical research or other pharmacovigilance roles at other companies and clinical research organizations. One DS professional moved to Celgene as they wanted to work in a multinational focused in oncology and innovative medication. Another DS professional ended up in pharmacovigilance after initially planning to work as a clinical research associate.

Answers to this question indicated that the first contact with pharmacovigilance was unintentional but as the professionals entered the roles, they found the industry to be exciting and to have purpose.

\subsubsection{Question 6: If you have recently transitioned in a role in Celgene, what role did you move from and where are you now?}

Two of the Celgene DS professionals had experienced a role transition at Celgene in 2017. One had been working in case management in a role requiring data entry, triage and assessment of cases and moved to a role as an SME in the development of AI-assisted technology. Another was acting as a manager in case management, overseeing staff in receipt and follow-up of cases as well as submission of cases to health authorities; their role changed to one requiring oversight of pharmacovigilance in the local DS offices.

\subsubsection{Question 7: What was your work experience before your current role?}

The DS professionals had backgrounds either in the healthcare industry or in clinical research positions.

\subsubsection{Question 8: What skills and competencies do you feel you have that allow you to perform the tasks in your role?}

The DS professionals had at least four of the six listed skills (see the ESM), which included knowledge of applicable national pharmacovigilance legislation (Good Pharmacovigilance Practices [GVP], International Council for Harmonisation of Technical Requirements for Pharmaceuticals for Human Use-Good Clinical Practice [ICHGCP]); understanding of global regulatory requirements for pharmacovigilance (FDA, European Medicines Agency [EMA], Therapeutic Goods Administration [TGA]), proficiency in technical legacy safety systems; working knowledge of Medical Dictionary for Regulatory Activities (MedDRA $^{\circledR}$ ) and World Health Organization Drug Dictionary (WHODrug) coding dictionaries and medical terminology; clinical knowledge of the therapeutic area and patient populations; and knowledge of aggregate safety data utilization.

Each of the DS professionals had at least 9 of the 12 competencies listed, which include staff management; team work and fostering team work; attention to detail; organization and teamwork; influencing and leadership skills in the training community; promoting open communication; engaging with external stakeholders and health authorities; ability to manage time, priorities and resources to achieve goals (high case volumes); ability to convey facts and ideas verbally and in writing; good interpersonal skills; good presentation skills and strong analytical skills. 


\subsubsection{Question 9: If you have recently transitioned in a role in Celgene, how do you feel your skills and competencies adapted or changed?}

The two DS professionals who transitioned in their roles at Celgene found they had to develop certain skills and competencies. Pharmacovigilance and work practice knowledge carried over to the new roles, but additional skills required included good communication and influencing skills to be able to work with internal and external stakeholders. New work environments and structures required new ways of managing time and prioritizing work.

\subsubsection{Question 10: If you could tailor a job description to your personal strengths and interests, what would it look like?}

The Celgene DS professionals all showed interest in further development aligned with their own skills, strengths and interests. Common reasons for not pursuing career aspirations was a lack of time and constraints on resources to be able to pursue these types of enhanced pharmacovigilance roles. Some examples of envisioned roles or aspirations included acting as internal or external pharmacovigilance ambassadors; and focusing on greater involvement with other work functions, where they could provide value in the form of new insights from pharmacovigilance data and be able to assist with company decisions and strategies for patient care and safety. The common theme was improved patient outcomes and the application of skills toward less task-orientated roles. Other examples included exploring other career pathways that involved epidemiology and proactive methods of ensuring better outcomes for patient populations.

\subsubsection{Question 11: How would you like your role to evolve and adapt to the future where Al-assisted technology augments how you do your work?}

The DS professionals were interested in career development and progressing to roles that steered away from administrative tasks where focus was on receipt or data entry of information from ICSRs into a database. They felt their skills and competencies were better used and applied in other areas of the pharmacovigilance function. Certain DS professionals showed interest in project management and cross-functional work or interactions with health authorities. DS professionals showed a desire to be involved in the promotion of Celgene DS and providing education on the new AI technology in the company among DS professionals and in other functions, as well as building trust with health authorities by providing them with robust data and results.

\subsubsection{Question 12: What skills and competencies would you like to develop or learn in order to perform your job in the future where Al assists you to do your work?}

The DS professionals were curious about AI and ML technology in pharmacovigilance and were interested in learning more about the computer science theory behind it. Some suggested a crash course in computer science or programming to understand how AI and ML works. DS professionals expressed curiosity about exactly how the program would work and the building blocks behind it. Some DS professionals were interested in additional soft skill development such as coaching of staff and improving their own presentation or communication skills.

\subsection{Conclusions}

The interview results suggest there is a keenness to shift pharmacovigilance work from volume-based administrative tasks to value-based work. Volume of work also appeared to restrict the development of pharmacovigilance core competencies for further career mastery. The vision of all interviewees was one in which pharmacovigilance resources, time and skills were better used and applied to ultimately achieve better patient outcomes.

With the appropriate steps, the future of harnessing and utilizing pharmacovigilance talent is promising in an environment where DS professionals are assisted by AI in their daily work.

\section{Discussion}

\subsection{Artificial Intelligence in Pharmacovigilance}

Use of technology on scale may enable the pharmacovigilance industry to increase operational efficiency and the consistency of data quality when processing ICSRs.

An interviewee stated "Aside from the obvious case volume challenges, I think one of the main challenges is separating the needles from the haystack. Making sense of the huge amount of information we currently have and the enormous amount of untapped information in registries, social media, Excel sheets, literature out there. But also going even further, linking other data sources to this data to make even more sense of it and start looking for relationships other than drug-drug interactions or drug-adverse event relationships. Maybe even moving into predictive models."

ML has the potential to enhance and increase the efficiency of DS professionals' work by augmenting decisionmaking processes when viewing machine predictions in 
machine-readable documents. This could allow DS experts to focus on other aspects of pharmacovigilance.

\subsection{New Core Competencies}

As AI is introduced to pharmacovigilance, what new skills and competencies are required? Using the model proposed by King [9] for core competencies and skill sets of the DS/ pharmacovigilance professional, we propose the skills listed in Table 2. These core competencies are not considered allinclusive for the field of computer science but serve as an indication of what skills a DS professional should acquire to work with $\mathrm{AI}$ in pharmacovigilance.

Why would a DS professional need to be proficient in understanding AI? Given the principles set out by King's model [9] of the DS/pharmacovigilance professional core competencies and skill sets, a DS professional should be able to understand and interact with the safety database they are using. AI in pharmacovigilance is a novel concept and would require more effort and time to be invested in training personnel.

Pharmacovigilance professionals' job descriptions do not require them to have had formal training in AI; their backgrounds are typically in science, pharmacy and medicine. Advanced industry-level training courses do not cover AI [10]. Any knowledge is likely to be acquired on the job or through self-development.

\subsection{Organizational Considerations}

If an organization decides to adopt assistive technology or AI, consideration from a change management perspective would need to include how to equip DS professionals with skills that would enable them to understand, use and troubleshoot the technology. The organization may decide to create new support roles for pharmacovigilance operations that can understand the technology, troubleshoot findings and resolve any errors with the ML algorithms. Further research and analysis would be required to fully describe these types of support roles.

\subsection{Glossary of Terms}

- Artificial intelligence (AI): A branch of computer science dealing with the simulation of intelligent behavior in computers.

- Augmented intelligence (IA): An alternative conceptualization of AI that focuses on AI's assistive role, emphasizing that it is designed to enhance human intelligence rather than replace it.

- Cognitive computing: A cognitive service is a mixture of ML and natural language processing (NLP) algorithms to solve a given problem that requires human cognition.

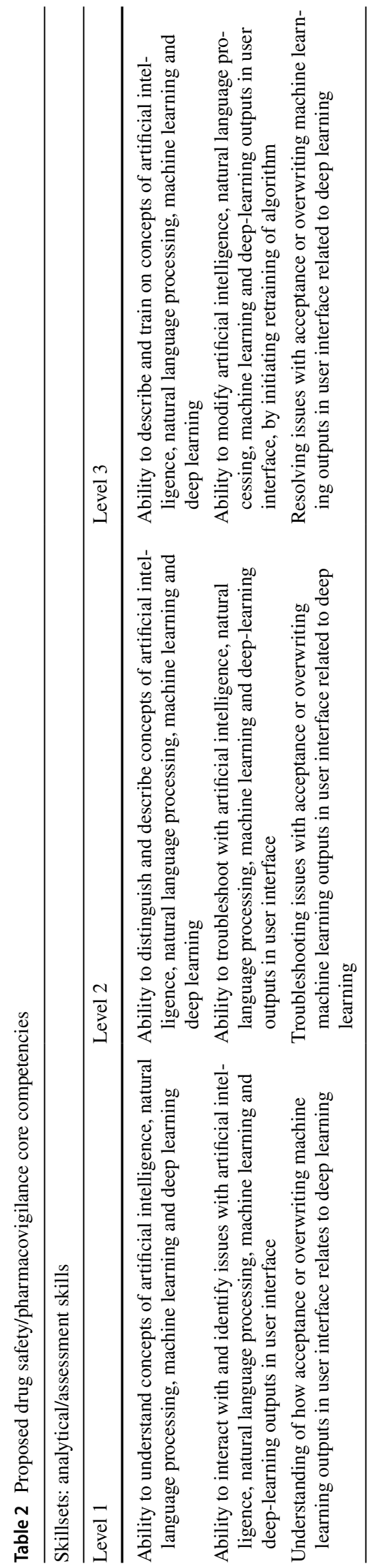


- Deep learning: The latest advancement in the ML domain, focusing on learning data representation. It aims to develop algorithms that are more generalizable as opposed to task specific.

- Natural language processing: The subfield in computer science that intends to teach computers to understand, interpret and manipulate the human language. Most NLP tasks leverage the capabilities of ML to achieve their objective.

- Machine learning and machine learning algorithms: A subfield of computer science that learns patterns from data without providing explicit programming instructions to create algorithms. This allows software applications to become more accurate in predicting outcomes without being explicitly programmed. The basic premise of ML is to build algorithms that can receive input data and use statistical analysis to predict an output while updating outputs as new data become available.

\section{Compliance with Ethical Standards}

Conflicts of interest Karolina Danysz is a paid employee of Celgene International Sàrl, Switzerland, working as a Senior Drug Safety Innovation Specialist. Salvatore Cicirello, Edward Mingle, Bruno Assuncao, Niki Tetarenko, Ruta Mockute, Danielle Abatemarco, Mark Widdowson, and Sameen Desai are employees of Celgene Corporation. All authors and those interviewed as part of this research were employees of Celgene Corporation at the time this paper was written and have no other potential conflicts of interest that are directly relevant to the contents.

Funding No funding was used to assist in the preparation of this article.

Open Access This article is distributed under the terms of the Creative Commons Attribution-NonCommercial 4.0 International License (http://creativecommons.org/licenses/by-nc/4.0/), which permits any noncommercial use, distribution, and reproduction in any medium, provided you give appropriate credit to the original author(s) and the source, provide a link to the Creative Commons license, and indicate if changes were made.

\section{References}

1. Celgene. Chrysalis Fact Sheet. https://www.celgene.com/newsr oom/media-library/chrysalis-fact-sheet/. Accessed 26 Sep 2018.

2. Journal Sentinel. Analysis: Reports of drug side effects increase fivefold in 12 years. https://www.jsonline.com/story/news/inves tigations/2017/03/17/analysis-reports-drug-side-effects-see-major -increase/99211376/. Accessed 20 Sep 2018.

3. Botsakos G. The future of pharmacovigilance:five imperatives that will drive improved business outcomes. Cognizant Business Consulting website. https://www.cognizant.com/industries-resources/ life_sciences/The-Future-of-Pharmacovigilance-Five-Imperative s-that-Will-Drive-Improved-Business-Outcomes.pdf. Accessed 28 Nov 2017.

4. Frey CB, Osborne MA. The Future of Employment. Technological forecasting and social change. 2016; 114:254-280. http://www. pewinternet.org/2016/03/10/public-predictions-for-the-future-ofworkforce-automation/. Accessed 20 Sep 2018.

5. Marr B. Instead of destroying jobs intelligence (AI) is creating new jobs in 4 out of 5 companies. Forbes website. https://www. forbes.com/sites/bernardmarr/2017/10/12/instead-of-destroying -jobs-intelligence-ai-is-creating-new-jobs-in-4-out-of-5-compa nies/\#58d27da7120d. Accessed 28 Nov 2017.

6. Merriam-Webster. Artificial Intelligence. https://www.merriamwebster.com/dictionary/artificial\%20intelligence. Accessed 20 Sep 2018.

7. The Expert System. What is Machine Learning? A definition. https://www.expertsystem.com/machine-learning-definition/. Accessed 20 Sep 2018.

8. PIPA. Competency Areas for Pharmacovigilance Professionals. https://www.pipaonline.org/write/MediaManager/Training/Compe tency_Areas_for_Pharmacovigilance_Professionals_May_2013. pdf. Accessed 26 Sep 2018.

9. King E. Core Competencies for Drug Safety/Pharmacovigilance Professionals.2011. https://cdr.lib.unc.edu/indexablecontent/ uuid:540d39d8-2d71-4f7a-af0a-c3863ee01dcb. Accessed 29 Sep 2018.

10. DIA. DIAglobal website. https://www.diaglobal.org/en/cours e-listing/elearning/modules/drug-safety. Accessed 29 Nov 2017. 